\title{
The Study of the Risk Factors of Health Care - Associated Infections in Patients' Care with Invasive Devices
}

\author{
Diana Platace*, Ilze Klava**, Lilija Antonevica***, Aigars Reinis****, Valentina Kuznecova ${ }^{* * * *}$, Juta Kroica****, Inga \\ Millere* \\ *Riga Stradins University, Riga, Latvia \\ ** Clinical University Hospital "Gailezers", Department of Clinical Physiology, Riga, Latvia \\ ***Department of Nursing, Pauls Stradins Clinical University Hospital, Riga, Latvia \\ **** Department of Biology and Microbiology, Riga Stradins University, Latvia \\ **Institute of Anatomy and Anthropology, Riga Stradins University, Latvia \\ ***Department of Pathology, Riga Stradins University, Latvia \\ ****Department of Reconstructive and Plastic Surgery, Austrumu Clinical University Hospital, Riga, Latvia
}

\begin{abstract}
Summary
Introduction. Health care-associated infections (HAls) are a major threat to patient safety. The spread of HAls cases in intensive care units (ICUs) and in surgical units is influenced by the severity of the patients' condition, as well as the number of invasive procedures and the environment of the units. The immune systems of critically ill patients are in a severe state which increases the probability of beneficial conditions for a colonisation by pathogenic microorganisms due to invasive procedures. Furthermore, the action of inserting an invasive device (urinary catheter, peripheral vein catheter) disrupts the natural defence mechanisms by itself.

Aim of the study. To determine risk factors of HAls during invasive procedures: peripheral vein catheter and urinary catheter insertion and care at the time.

Materials and methods. The research was performed in the ICUs and in the surgical units of Latvia's regional multi-profile hospitals $(n=3)$, using the quantitative research method: questionnaire $(n=188)$, and qualitative research methods: clinically structured empiric research $(n=45)$ and microbiological tests $(n=86)$ : a) with a Count-Tact applicator and a special culture medium, b) with a swab, and c) with catheter sedimentation method.

Results. The study results showed that surgical nurses take care of 18 to 40 patients per day, while intensive care nurses take care of 2 to 3 patients per day. A common problem identified in ICUs and in surgical units related to the lack of unified nursing protocols on performing invasive procedures in all cases (100\%; 45/45). Microbiological investigations showed a high level of bio-contamination during invasive procedures: the amount of microorganisms on the nurses' hands considerably exceeded the acceptable levels in all cases $(100 \% ; 4 / 4)$, and medium to high levels of bio-contamination were discovered on patient's changed bed sheets (100\%; $2 / 2)$ as well as in nurses' hair $(85.7 \% ; 48 / 56)$ and their work wear $(78.5 \% ; 44 / 56)$. In $25 \%$ of the observed cases Staphylococcus aureus was discovered in the sterile zone of the peripheral vein catheter 72 hours and 96 hours after the catheter's insertion. 72 hours after the catheter's insertion, as well as 7 days after the insertion of a urinary catheter, $100 \%$ of the cases revealed the presence of at least one and in some cases several of the following pathogens: Staphylococcus aureus, Pseudomonas aeruginosa, Escherichia coli, $\beta$ haemolytic Streptococcus and fungi, such as Candida albicans and Candida tropicalis.
\end{abstract}

Conclusions. The main risk factors of HAls in patients' care using invasive devices are: the lack of unified nursing protocols, aseptic and antiseptic mistakes and excessive workload, as well as a high level of bio-contamination in the ICUs and in surgical units.

Key words: invasive devices, health care-associated infections, urinary catheter, peripheral vein catheter.

\section{INTRODUCTION}

In contemporary medicine the invasive devices especially intravascular devices of all types and urinary catheters - continue to be essential for the management of critically ill patients (15). Invasive devices are far more important in determining susceptibility to health care-associated infections (HAIs) than the underlying diseases (7). The most common devicerelated infection pathogens are Staphylococcus aureus, Staphylococcus epidermidis, Klebsiella, Enterobacter, Serratia, Candida albicans, Pseudomonas aeruginosa, Citrobacter freudii Corynebacterium, Escherichia coli (8, 19, 22). Staphylococci, enterococci, and many other species of bacteria are known to attach to indwelling medical devices and form biofilms consisting of complex communities of single cells and microcolonies within a matrix of hydrated polysaccharides, proteins, and other macromolecules, including DNA. Within this matrix, bacterial cells evade the host immune response and survive antimicrobial chemotherapy, resulting in persistent infections that are difficult to treat $(2,20)$. The risk of device-related infection, more than anything else, has forced medicine to accept the necessity for infection control that can be very cost-effective. Intensive education and "bundling" of evidence-based interventions can reduce the infection rate through 
improved asepsis in handling and an earlier removal of invasive devices, but the maintenance of such gains requires ongoing efforts $(13,14)$.

\section{AIM OF THE STUDY}

The aim of the study was to determine risk factors of HAIs during invasive procedures: peripheral vein catheter and urinary catheter insertion and care at the time.

\section{MATERIALS AND METHODS}

The research was carried out in the intensive care units (ICUs) and in surgical units of Latvia's regional multiprofile hospitals $(n=3)$, using the quantitative research method: questionnaire $(n=188)$, and qualitative research methods: clinically structured empiric research $(n=45)$ and microbiological tests $(n=86)$. To determine the risk factors of HAIs from the care-givers' side (knowledge concerning patient care using invasive devices and the carrying-out of high-risk procedures, as well as practical skills concerning the daily care of patients by using invasive devices), a structured questionnaire was developed which contained predetermined (closed as well as open) questions with prepared answers and a clinically structured empiric research plan, which included: a) the observation of nurses' work activities when performing invasive procedures, and b) the inspection of the nurses' work environment (sufficient material and technical means, the presence or lack of nursing protocols and the number of nursing staff in the units). By means of microbiological investigation the contamination level of the ICUs and surgical units was determined: a) using a Count-Tact applicator and a culture medium specially selected for this method, the bio-contamination level of the work environment, work surfaces, nurses' work wear and patients' changed bed sheets were determined, b) the microbiological contamination of the equipment used in the invasive procedures and the care-giver's hands were determined by using the swab method, c) the microbial contamination of the invasive devices was analyzed by using the catheter sedimentation method. The samples taken with the aim of identifying bacterial species present were put on selective culture media. Interpretation of the Count-Tact method results was performed according to the risk level present and the colony forming unit (CFU) count on a $25 \mathrm{~cm}^{2}$ surface. The obtained data were analyzed with the help of the following software: SPSS 16.0 for MS Windows, and MS Office Excel.

\section{RESULTS}

In total were analyzed 188 questionnaires which included patients' care with peripheral vein catheters $(\mathrm{n}=100)$ and patients' care with urinary catheters $(\mathrm{n}=88)$. The obtained results by questionnaire showed that most of the nurses were informed about the hospital-developed guidelines for insertion and patients' care with peripheral vein catheters in 77 cases $(77 \%$; $\mathrm{n}=100$ ) and for insertion and patients' care with urinary catheters in 77 cases $(87.5 \% ; n=88)$ and adhered to these guidelines in their daily work. Data collected by clinically structured empiric research during cannulation of the peripheral vein and patients' care with peripheral vein catheters $(n=30)$, and urinary catheterization and patients' care with urinary catheters $(n=15)$ showed that cannulation of the peripheral vein in 16 cases $(53.3 \% ; n=30)$ and urinary catheterization in 5 cases $(33.3 \% ; n=15)$ were recorded in the ordination list, the patient's care protocol or the manipulation journal. Less than half of the observed nurses adhered to the principles of hand hygiene during invasive procedures: during the cannulation of the peripheral vein only 3 nurses $(10 \% ; n=30)$ treated their hands before putting on gloves and 10 nurses $(33.3 \% ; n=30)$ treated their hands after removing the gloves, but none of them used an adequate technique for treating their hands. By comparison, when dealing with insertion of urinary catheters, 3 nurses $(13.3 \% ; n=15)$ treated their hands before putting on gloves and 6 nurses $(40 \% ; n=15)$ treated their hands after removing the gloves, and 3 of them $(13.3 \%)$ used adequate hand-treating techniques (Fig. 1 and 2 ). In 23 cases (77\%; n=30) of the observed peripheral vein cannulation and in 4 cases $(27 \% ; n=15)$ of urinary catheterization, there was jewellery on the nurses' hands. Change of the peripheral vein catheters, not rarer than once in 72 hours, was observed in 25 cases $(83.3 \% ; n=30)$, the timely changing of urinary catheters - in 4 cases $(27 \% ; n=15)$ (Fig. 1 and 2). In 21 out of 30 cases $(70 \%)$ the patient's puncture dressing was dry and clean, but nine patients (30\%) had bloodsoaked or wet puncture dressings. An observation study showed that a nurse from the surgical units takes care of 18 to 40 patients per day and 2 to 3 patients per day in the case of ICUs. Microbiological investigation with the Count-Tact method of samples taken from the hands of ICU nurses before the cannulation of the peripheral vein determined that the number of microorganism colonies exceeds the acceptable levels as much as sixteen-fold (44 CFUs and 83 CFUs; $n=2$ ) (the permissible level on $25 \mathrm{~cm}^{2} \leq 5$ CFUs). The bio-contamination of the hands of nurses working in surgical units also exceeded acceptable levels as the $25 \mathrm{~cm}^{2}$ surface produced more than 200 colony forming units (128 CFUs and 241 CFUs; $\mathrm{n}=2$ ) (permissible level on $25 \mathrm{~cm}^{2} \leq 50$ CFUs) (Table 1). Microbiological investigation of the patients' changed bed sheets and nurses' work wear performed with the Count-Tact method during urinary catheterization revealed a medium to high level of bio-contamination: the number of bacteria colonies on work wear exceeded the norm in 44 of the investigated cases $(78.5 \%$; $\mathrm{n}=56)$, Mucor fungi were found in 44 cases $(78.5 \%$; $\mathrm{n}=56$ ) and the bacteria colonies count in the nurses' hair exceeded permissible levels in 48 cases $(85.7 \%$; $\mathrm{n}=56$ ) (Table 2). The microbiological investigation of the urinary catheters' connection with the collector 72 $\mathrm{h}$ and 7 days after the insertion of the catheters showed that in 6 cases $(50 \%)$ pathogenic microorganisms like the E. coli, $\beta$ haemolytic Streptococcus spp. and fungi, like the C.albicans were present (Table 4). The research performed with the swab method and by catheter 
sediment analysis $72 \mathrm{~h}$ and $96 \mathrm{~h}$ after the insertion of a peripheral vein catheters revealed the presence of such pathogens as Pseudomonas aeruginosa, Staphylococcus aureus in the sterile zone of the peripheral vein catheter in one case $(25 \%)$. Likewise the analysis of the urinary catheter sediments showed the presence of pathogens like S.aureus, P.aeruginosa, E.coli, $\beta$ haemolytic Streptococc us spp. and fungi like C.albicans and C.tropicalis in 6 cases $(100 \%)$ both after 72 hours and 7 days of the insertion of the catheter (Tables 3 and 4 ).

\section{DISCUSSION}

Prevention of health care-associated infections is the key procedure in quality of patients care. The study of risk factors in patients' care with invasive devices is essential for evaluation of current infection prevention activities and for planning further interventions in units and in hospital levels as well as at national level. Obtained results help to identify risk factors for HAIs and to optimize the hospital work, the use of more efficient and financially advantageous methods for their prevention. This is the first report on risk factors for HAIs in patients' care with indwelling medical devices in Latvia.

Every nurse can play a significant role in minimizing the risk of devices- related infections. An important factor in the nurses' daily work is an adequate distribution of work shifts and duties, because excessive workloads are a risk factor for HAI (9). Our studies confirmed the excessive workload in nurses' daily work, which significantly exceeded the limits of patients' care (1-2 patients per nurse in ICU and 15 patients per nurse in surgical units). As shown by several studies, a significant role in limiting the risk of HAIs are care guidelines and nursing protocols for the development and implementation in practice $(6,11,13,16,18)$. Our results showed that a common problem in ICUs and in surgical units is the lack of unified nursing protocols on performing invasive procedures. More and more, the authors support the principle of adequate hand hygiene, because many hospital personnel fail to follow basic infection control, such as hand washing between patients' contacts (4, $10,21)$. In our studies, less than half of the observed nurses adhered to the principles of hand hygiene during invasive procedures and microbiological investigations showed a high level of bio-contamination during invasive procedures. The amount of microorganisms on the nurses' hands exceeded the acceptable levels sixteenfold, and medium to high levels of bio-contamination were discovered on patient's changed bed sheets as well as in nurses' hair and their work wear. Our data demonstrate some evidence that the pathogenic flora ( $\beta$ haemolytic Streptococcus, E. coli) remains unchanged both $72 \mathrm{~h}$ and 7 days after the insertion of the urinary catheter. It leads to the conclusion that the urinary catheter is contaminated during the first 72 hours after insertion and should be changed at least once every 72 hours instead of once a week as indicated by the manufacturer of the catheters. However, most of devices-related infections are not severe and self- limiting, and microbiological investigations in such cases are not performed routinely in regional multiprofile hospitals of Latvia. Conclusions of epidemiologic research are inconsistent when evaluating the effect of changing intravascular or urinary artificial implants less frequently than once every 72 hours. Some authors point out that 24 hours is a sufficient period of time for a biofilm to form on the catheter surface, consisting of microorganisms such as Staphylococcus epidermidis, Staphylococcus aureus, Pseudomonas aeruginosa, etc. making the catheter a source of bacteremia $(1,5)$. Nevertheless the frequency of changing the catheters should not be considered as the main cause of HAI development, since more attention should be paid to antiseptics and aseptics during the patients' care with invasive devices (17).

Regardless of all previously mentioned, the rate of HAIs in multi-profile hospitals of Latvia is comparable to that of in the developed countries (3).

\section{CONCLUSIONS}

The following HAIs risk factors in patients' care with invasive devices were determined: 1) lack of unified nursing protocols on performing invasive procedures in the intensive care units and in surgical units, 2) disregard of basic principles of hand hygiene while carrying out invasive procedures, 3) antiseptic and aseptic mistakes during patients' care with invasive devices, 4) excessive workload of nurses working in ICUs and in surgical units, 5) high levels of microbiological contamination during invasive procedures, including medium to high levels of bio-contamination of changed patients' bed sheets, nurses' work wear and hair.

\section{ACKNOWLEDGEMENTS}

This study was supported by the project of European Social Fond (ESF).

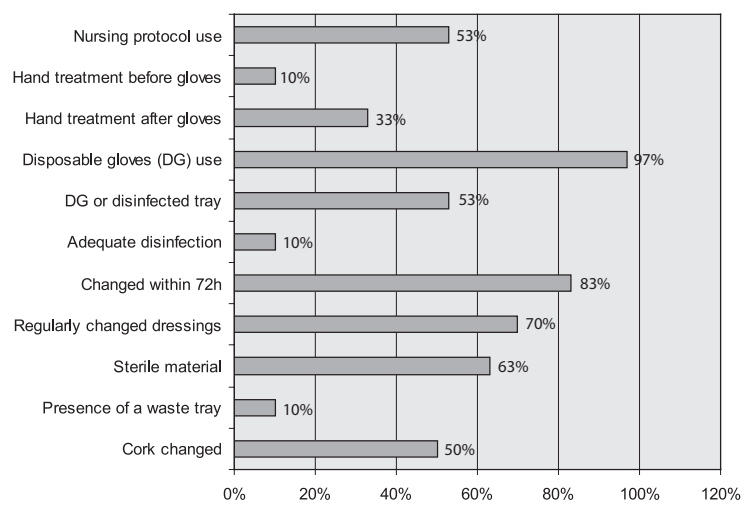

Fig. 1. Cannulation of the peripheral veins and patients' care with peripheral venous catheter (clinically structured empiric research, $\mathrm{n}=30$ ) 


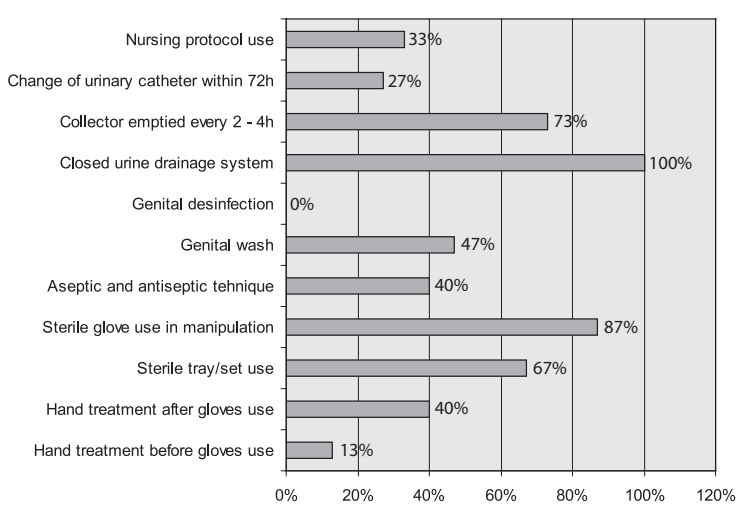

Fig. 2. Urinary catheterisation and patients' care with urinary catheter (clinically structured empiric research, $n=15$ )

Table 1. Microbiological investigation with a Count-Tact method (samples taken prior to the introduction of a PVC, $n=4$ )

\begin{tabular}{|l|l|}
\hline Object & Obtained results \\
\hline $\begin{array}{l}\text { Hands of a surgical unit } \\
\text { nurse in clinic A }\end{array}$ & 241 colonies on $25 \mathrm{~cm}^{2}$ \\
\hline $\begin{array}{l}\text { Hands of a surgical unit } \\
\text { nurse in clinic B }\end{array}$ & 128 colonies on $25 \mathrm{~cm}^{2}$ \\
\hline $\begin{array}{l}\text { Hands of a ICU nurse in } \\
\text { clinic A }\end{array}$ & 44 colonies on $25 \mathrm{~cm}^{2}$ \\
\hline $\begin{array}{l}\text { Hands of a ICU nurse in } \\
\text { clinic B }\end{array}$ & 83 colonies on $25 \mathrm{~cm}^{2}$ \\
\hline
\end{tabular}

Table 2. Microbiological investigation with a Count-Tact method (samples taken prior to the insertion of a urinary catheter, $n=6$ )

\begin{tabular}{|l|l|}
\hline Object & Obtained results \\
\hline $\begin{array}{l}\text { Procedural trolley, sterile tray, } \\
\text { set in ICUs of clinic A and B }\end{array}$ & 0 colonies on $25 \mathrm{~cm}^{2}$ \\
\hline $\begin{array}{l}\text { Patient's changed bed sheets } \\
\text { in ICU of clinic A }\end{array}$ & $\begin{array}{l}1000 \text { colonies } \\
\text { on } 25 \mathrm{~cm}^{2}\end{array}$ \\
\hline $\begin{array}{l}\text { Patient's changed bed sheets } \\
\text { in ICU of clinic B }\end{array}$ & 15 colonies on $25 \mathrm{~cm}^{2}$ \\
\hline $\begin{array}{l}\text { Nurse's work wear in ICU of } \\
\text { clinic A }\end{array}$ & 100 colonies on $25 \mathrm{~cm}^{2}$ \\
\hline $\begin{array}{l}\text { Nurse's work wear in ICU of } \\
\text { clinic B }\end{array}$ & 69 colonies on $25 \mathrm{~cm}^{2}$ \\
\hline
\end{tabular}

Table 3. Microbiological investigation performed using the catheter sedimentation method $(n=4)$

\begin{tabular}{|l|l|l|l|}
\hline No. & Object & $\begin{array}{l}\text { Blood } \\
\text { agar } \\
\text { medium }\end{array}$ & $\begin{array}{l}\text { Chrom } \\
\text { Agar } \\
\text { Candida } \\
\text { medium }\end{array}$ \\
\hline $\begin{array}{l}\text { Sample } \\
1\end{array}$ & $\begin{array}{l}\text { Patient - male, 35 yrs. } \\
\text { o., Surgical unit in } \\
\text { clinic A } \\
\text { Dg. Amputation of } \\
\text { left leg } \\
\text { PVC introduced 96 h } \\
\text { ago }\end{array}$ & $\begin{array}{l}\text { Staphy- } \\
\text { lococcus } \\
\text { aureus }\end{array}$ & Negative \\
\hline $\begin{array}{l}\text { Sample } \\
2\end{array}$ & $\begin{array}{l}\text { Patient - male, 53 yrs. } \\
\text { o. ICU in clinic A } \\
\text { Dg. Hemorrhagic } \\
\text { stroke. } \\
\text { PVC introduced 72 h } \\
\text { ago }\end{array}$ & Negative & Negative \\
\hline $\begin{array}{l}\text { Sample } \\
3\end{array}$ & $\begin{array}{l}\text { Patient - male, 22 yrs. } \\
\text { o. ICU in clinic B } \\
\text { Dg.Polytrauma after a } \\
\text { traffic accident. } \\
\text { PVC introduced 72 h } \\
\text { ago }\end{array}$ & $\begin{array}{l}\text { Negative } \\
\text { Patient - male, 40 yrs. } \\
\text { o. Surgical unit in } \\
\text { clinic B } \\
\text { Dg. Osteomyelitis of } \\
\text { left shin. } \\
\text { PVC introduced 96 h } \\
\text { ago }\end{array}$ & Negative \\
\hline $\begin{array}{l}\text { Samplive } \\
4\end{array}$ & Negative \\
\hline
\end{tabular}


Table 4. Microbiological investigation performed using the catheter sedimentation method and swab $(n=12)$

\begin{tabular}{|c|c|c|c|c|c|}
\hline No. & Object & $\begin{array}{l}\text { OESA } \\
\text { medium }\end{array}$ & $\begin{array}{l}\text { P.aeroginosa } \\
\text { medium }\end{array}$ & $\begin{array}{l}\text { Chrom } \\
\text { Agar } \\
\text { medium }\end{array}$ & Bloodagar medium \\
\hline Sample 1 & $\begin{array}{l}\text { Connection between collector and } \\
\text { catheter after } 72 \mathrm{~h} \text { (ICU, clinic A) }\end{array}$ & Neg. & Neg. & Neg. & $\begin{array}{l}\beta \text { haemolytic } \\
\text { Streptococcus, E. coli }\end{array}$ \\
\hline Sample 2 & $\begin{array}{l}\text { Biomaterial sample taken from the } \\
\text { catheter after } 72 \mathrm{~h} \\
(\mathrm{ICU}, \text { clinic } \mathrm{A})\end{array}$ & Positive & Neg. & C. albicans & $\begin{array}{l}\beta \text { haemolytic } \\
\text { Streptococcus, } \\
\text { Staphylococcus aureus }\end{array}$ \\
\hline Sample 3 & $\begin{array}{l}\text { Connection between collector and } \\
\text { catheter after } 7 \text { days (ICU, clinic A) }\end{array}$ & Neg. & Neg. & Neg. & Neg. \\
\hline Sample 4 & $\begin{array}{l}\text { Biomaterial sample taken from the } \\
\text { catheter after } 7 \text { days (ICU, clinic A) }\end{array}$ & Neg. & Neg. & C. albicans & $\begin{array}{l}\beta \text { haemolytic } \\
\text { Streptococcus, } \\
\text { Staphylococcus aureus }\end{array}$ \\
\hline Sample 5 & $\begin{array}{l}\text { Connection between collector and } \\
\text { catheter after } 72 \mathrm{~h} \text { (ICU, clinic B) }\end{array}$ & Neg. & Neg. & Neg. & Neg. \\
\hline Sample 6 & $\begin{array}{l}\text { Biomaterial sample taken from the } \\
\text { catheter after } 72 \mathrm{~h} \\
\text { (ICU, clinic B) }\end{array}$ & Neg. & Neg. & Neg. & E. coli \\
\hline Sample 7 & $\begin{array}{l}\text { Connection between collector and } \\
\text { catheter after } 7 \text { days (ICU, clinic B) }\end{array}$ & Neg. & Neg. & Neg. & $\begin{array}{l}\beta \text { haemolytic } \\
\text { Streptococcus }\end{array}$ \\
\hline Sample 8 & $\begin{array}{l}\text { Biomaterial sample taken from the } \\
\text { catheter after } 7 \text { days (ICU, clinic B) }\end{array}$ & Neg. & Neg. & C. tropicalis & E. coli \\
\hline Sample 9 & $\begin{array}{l}\text { Connection between collector and } \\
\text { catheter after } 72 \mathrm{~h} \text { (ICU, clinic C) }\end{array}$ & Neg. & Neg. & Neg. & $\begin{array}{l}\beta \text { haemolytic } \\
\text { Streptococcus, E. coli }\end{array}$ \\
\hline Sample 10 & $\begin{array}{l}\text { Biomaterial sample taken from the } \\
\text { catheter after } 72 \mathrm{~h} \\
\text { (ICU, clinic C) }\end{array}$ & Neg. & Positive & Neg. & $\begin{array}{l}\beta \text { haemolytic } \\
\text { Streptococcus }\end{array}$ \\
\hline Sample 11 & $\begin{array}{l}\text { Connection between collector and } \\
\text { catheter after } 7 \text { days (ICU, clinic C) }\end{array}$ & Neg. & Neg. & C. albicans & Neg. \\
\hline Sample 12 & $\begin{array}{l}\text { Biomaterial sample taken from the } \\
\text { catheter after } 7 \text { days (ICU, clinic C) }\end{array}$ & Neg. & Neg. & C. albicans & Neg. \\
\hline
\end{tabular}

\section{Conflict of interest: None}




\section{REFERENCES}

1. Donlan RM. Biofilms and Device-Associated Infections // Emerg Infect Dis, 2001; 7:277 - 281

2. Donlan RM. Biofilms on central venous catheters: is eradication possible? // Curr Top Microbiol Immunol, 2008; 322:133 - 161

3. Dumpis U, Balode A, Vigante D, Narbute I, Valinteliene R, Pirags V, Martinsons A, Vingre I. Prevalence of nosocomial infections in two Latvian hospitals // Euro Surveill, 2003; 8:73 - 78

4. Farmer JC. Notice: all employees must wash hands before returning to work // Crit Care Med, 2009; 37:2307 - 2309

5. Ferrieres L, Hancock V, Klemm P. Specific selection for virulent urinary tract infectious Escherichia coli strainsduring catheter-associatedbiofilmformation // FEMS Immunol Med Microbiol, 2007; 51:212 -219

6. Gotelli JM, Merryman P, Carr C, McElveen L, Epperson C, Bynum D. A quality improvement project to reduce the complications associated with indwelling urinary catheters // Urol Nurs, 2008; 28:465 - 467

7. Graves N, McGowan JE. Nosocomial infection, the deficit reduction acts, and incentives for hospitals // JAMA, 2008; 30:1577 - 1579

8. Guidelines for the Prevention of Intravascular Catheter- Related Infections // MMWR, 2002; $1-26$

9. Hugonnet S, Chevrolet J.C, Pittet D. The effect of workload on infection risk in critically ill patients // Crit Care Med, 2007; 35:76-81

10. Kusachi S, Sumiyama Y, Arima Y et al. Creating a manual for proper hand hygiene and its clinical effects //Surg Today, 2006; 36:410 - 415

11. Loeb M, Hunt D, O'Halloran K, Carusone SC, Dafoe $\mathrm{N}$, Walter SD. Stop orders to reduce inappropriate urinary catheterization in hospitalized patients: a randomized controlled trial // J Gen Intern Med, 2008; 23:816-820

12. Maki DG, Mermel LA. Infections due to infusion therapy // In: Bennet JV., Brachman PS. Hospital Infections. 4th ed. Philadelphia: Lippincott Williams\&Wilkins; 1998; $689-724$

13. Morris W., Hong Toy M., Strategies for preventing peripheral intravenous cannula infection // $\mathrm{Br} \mathrm{J}$ Nurs, 2008; 10:14-21
14. Moureau NL. Reducing the cost of catheter-related bloodstream infections // Nursing, 2009; 39: $14-15$

15. Pittet D, Harbarth SJ. The Intensive care unit // In: Bennet JV., Brachman PS. Hospital Infections. 4th ed. Philadelphia: Lippincott Williams\&Wilkins; 1998; $456-465$

16. Quattrin R, Peacile A, Conzut L, Majori S, Brusaferro $S$ and the Gisio group. Infection control nurse: a national survey // J Nurs Manag, 2004; $12: 375-380$

17. Ramritu P, Halton K, Cook D, Whitby M, Graves N. Catheter-related bloodstream infections in intensive care units: a systematic review with meta-analysis // J Adv Nurs, 2008; 62:3 - 21

18. Saint S, Meddings JA, Calfee D, Kowalski CP, Krein SL. Catheter-associated urinary tract infection and the Medicare rule changes // Ann Intern Med, 2009; 150:877 - 884

19. Stamm WE. Urinary tract infections // In: Bennet JV., Brachman PS. Hospital Infections. 4th ed. Philadelphia: Lippincott Williams\&Wilkins; 1998; $477-486$

20. Weigel LM, Donlan RM, Shin DH, Clark B, McDougal LK, et al. High-level vancomycin-resistant Staphylococcus aureus associated with a polymicrobial biofilm // Antimicrob Agents Chemother, 2007; $51: 231-238$

21. Weinstein RA. Nosocomial infection update // Emerg Infect Dis, 1998; 4:416-420

22. Wilson J. Microorganisms and their control // In: Wilson J. Infection control in clinical practice. 3rd ed. London: Elsevier; 2006; 119 - 131

\section{Address:}

Diana Platace

Faculty of Nursing

Riga Stradins University

16 Dzirciema Street,

Riga, Latvia, LV-1007

E-mail: diana.platace@inbox.lv 